\title{
A Cipher Design using the Combined Effect of Arithmetic and Logic Operations with Substitutions and Transposition Techniques
}

\author{
S.G.Srikantaswamy \\ Research Scholar \\ National Institute of Engineering, Mysore
}

\author{
Prof. H. D. Phaneendra \\ Research Guide \& Professor, Department of CS \\ National Institute of Engineering, Mysore
}

\begin{abstract}
Communication is a basic process of exchanging information. Information security is a very important aspect now a day. The introduction of internet and distributed system made the information security issue more challenging and complex. Cryptography plays a crucial role in providing security to data transmitted over the internetwork. Encryption is the most widely used technique used to scramble the data that is being transmitted over the network from sender to a receiver. The encryption algorithms are available practically and provide the security for user data and information. This paper presents an advanced encryption technique which combines the features of substitution and transposition. Five different key values being used in this algorithms and each key value is used to substitute the corresponding plaintext characters in association with addition operation. Each key value is twice as that of the previous one. The basic key value is a fixed one defined by the user. The transposition technique is employed by left shifting each bit of the data. The shifted data is complemented to alter the each bit of the cipher text that is being generated. The effort of the algorithm is to make the cryptanalysis difficult and to make the algorithm stronger.
\end{abstract}

\section{Keywords}

Information Security, Plaintext, Ciphertext, Key, Cipher, Substitution, Transposition.

\section{INTRODUCTION}

A Cryptosystem for a specified task is secure if no adversary of a specified power can achieve a specified break.[6].All cryptosystems are based on two general principles: Substitution, in which each element in the plaintext is mapped in to another element and , Transposition, in which characters in the plaintext are rearranged.[4] .Many encryption and decryption algorithms are widely available and being used for encrypting and decrypting the data $[4,5,6]$. Many encryption algorithm incorporates both substitution and transposition techniques $[1,2,3]$. Substitution cipher involves the replacing one or more characters in a message with one or more other entities may be other characters, symbols and numbers. There are several types of substitution ciphers available in the field of network security [4].Monoalphabetic substitution involves replacing each character or letter in the given message with another character of the alphabet. Polyalphabetic substitution involves the following features:A set of related monoalphabetic substitution rules is used.

\begin{abstract}
- A key determines which particular rule is chosen for a given transformation.
\end{abstract}

In this paper, an encryption algorithm which incorporates the features of both substitution and transposition technique is proposed. To encrypt a message, a key value $\mathrm{K}$ is assumed. The first character of the message is added with the key value. The resultant value is then left shifted once. The left shifted value is then complemented using the logical NOT operation. The resultant complemented value is the final ciphertext value for the corresponding plaintext character. The second character is encrypted in the same manner but with a key value $2 * \mathrm{~K}$. The third character is complemented using the key value $3 * \mathrm{~K}$. The fourth character by $4 * \mathrm{~K}$ and fifth by $5^{*} \mathrm{~K}$. The sixth character by $\mathrm{K}$, Seventh character by $2 * \mathrm{~K}$ and so on, with the value of $\mathrm{K}_{\mathrm{j}}$, where $1 \leq \mathrm{j} \leq \bmod 6$. The organization of the paper is gives as follows: Section 2 provides the complete encryption process details. Section 3 gives encryption algorithm details. Section 4 gives encryption and decryption results. Section 5 provides the features of the proposed scheme and Section 6 provides conclusions drawn from the analysis carried out on the above desired encryption and decryption algorithm. Section 7 gives references.

\section{ENCRYPTION PROCESS}

Consider a plaintext message say "NETWORK". Let the key be $\mathrm{K}$. Now the five different versions of key values are derived based on first key value. Consider the first character of the plaintext message $\mathrm{P}_{\mathrm{i}}$. Let the key value used to substitute the first character of the plaintext be $K_{j}$, where $K_{j}=K$ and $1 \leq \mathrm{i} \leq \mathrm{n}$ and $1 \leq \mathrm{j} \leq \bmod 6$. The resultant substituted value of the plaintext is left shifted by one position. The shifted value of the plaintext is complemented to obtain the final ciphertext value for corresponding value of the plaintext $\left(\mathrm{P}_{\mathrm{i}}\right)$. Now for the plaintext character $P_{2}$, the key value is used is $K_{2}$ where $K_{2}=$ $2 * \mathrm{~K}$. The above procedure is repeated to obtain $\mathrm{C}_{2}$. Similarly to obtain $\mathrm{C}_{3}$ from $\mathrm{P}_{3}$, the key value used will be $\mathrm{K}_{3}=3 * \mathrm{~K}$, for $\mathrm{C}_{4}$, key $\mathrm{K}_{4}=4 * 4$, and finally for $\mathrm{C}_{5}$, key $\mathrm{K}_{5}=5 * \mathrm{~K}$. Now for sixth character of the given message key value used will be $\mathrm{K}_{1}$, for seventh character $K_{2}$ and so on. The value of $i$ and $j$ are such that $1 \leq \mathrm{i} \leq \mathrm{n}, \mathrm{j} \leq 1 \leq \bmod 6$. 


\section{ENCRYPTION ALGORITHM}

Step 1: Start

Step 2: Input the plaintext message $\mathrm{P}_{\mathrm{i}}, 1 \leq \mathrm{i} \leq \mathrm{n}$.

Step 3: Declare the key value K.

Step 4: Generate 5 different key values $\mathrm{K}_{\mathrm{j}}, 1 \leq \mathrm{j} \leq \bmod 6, \mathrm{~K}_{1}$

$=\mathrm{K}, \mathrm{K}_{2}=2 * \mathrm{~K}, \mathrm{~K}_{3}=3 * \mathrm{~K}, \mathrm{~K} 4=4 * \mathrm{~K}, \mathrm{~K} 5=5 * \mathrm{~K}$;

Step 5: $\mathrm{C}_{\mathrm{i}}=\mathrm{P}_{\mathrm{i}}+\mathrm{K}_{\mathrm{j}}$;

Step 6: Repeat for $\mathrm{i}=1$ to $\mathrm{n}$

$$
\begin{aligned}
& \mathrm{j}=1 \text { to mod } 6 \\
& \mathrm{C}_{\mathrm{i}}=\mathrm{P}_{\mathrm{i}}+\mathrm{K}_{\mathrm{j}} ; \\
& \mathrm{C}^{1}{ }_{\mathrm{i}}=\text { Left shift }\left(\mathrm{C}_{\mathrm{i}}\right) ; \\
& {\left[\mathrm{C}_{\mathrm{i}}\right]_{\text {final }}=\text { One's Complement of }\left[\mathrm{C}^{1} \mathrm{i}\right] \text {; }}
\end{aligned}
$$

\section{ENCRYPTION AND DECRYPTION RESULT}

\begin{tabular}{|c|c|c|c|c|c|c|}
\hline $\begin{array}{l}\text { Plaintext } \\
\text { Character }\end{array}$ & $\begin{array}{l}\text { ASCII } \\
\text { Value }\end{array}$ & Binary Equivalent & $\begin{array}{c}\text { Add key Value } \\
\text { Let } \mathrm{K}=25 \\
\mathrm{C}_{\mathrm{i}}=\mathrm{P}_{\mathrm{i}}+\mathrm{K}_{\mathrm{j}} \\
1 \leq \mathrm{i} \leq \mathrm{n} \\
\mathrm{j} \leq 1 \leq \bmod 6\end{array}$ & $\begin{array}{c}\text { Left } \\
\text { Shift } \\
C_{i} \\
=C_{i}^{1}\end{array}$ & $\begin{array}{c}\text { Complement } \\
\qquad \mathrm{C}^{1}{ }_{\mathrm{i}} \\
=\mathrm{C}_{\mathrm{i} \text { final }}\end{array}$ & $\begin{array}{c}\text { ASCII } \\
\text { Equivalent } \\
\text { value of } \\
\text { Ciphertext }\end{array}$ \\
\hline $\mathrm{N}$ & 46 & 01000111 & 71 & 10001110 & 01110001 & 113 \\
\hline $\mathrm{E}$ & 37 & 01010111 & 87 & 10101110 & 01010001 & 81 \\
\hline $\mathrm{T}$ & 52 & 01111111 & 127 & 11111110 & 00000001 & 01 \\
\hline $\mathrm{W}$ & 55 & 10011011 & 155 & 00110111 & 11001000 & 200 \\
\hline $\mathrm{O}$ & 47 & 10101100 & 172 & 01011001 & 10100110 & 166 \\
\hline $\mathrm{R}$ & 50 & 01001011 & 75 & 10010110 & 01101001 & 105 \\
\hline $\mathrm{K}$ & 43 & 01011101 & 93 & 10111010 & 01000101 & 69 \\
\hline
\end{tabular}

Example 1: Consider the plaintext message "NETWORK".

The Encryption and Decryption results produced by the Algorithm are as follows

Table 1: Encryption

Table 2: Decryption

\begin{tabular}{|c|c|c|c|c|c|c|}
\hline $\begin{array}{c}\text { ASCII } \\
\text { Equivalent value } \\
\text { of Ciphertext }\end{array}$ & $\begin{array}{c}\text { Binary } \\
\text { Equivalent } \\
\text { Of } \mathrm{C}_{\mathrm{i}}\end{array}$ & $\begin{array}{c}\text { Complement } \\
\mathrm{C}_{\mathrm{i}}\end{array}$ & $\begin{array}{c}\text { Right } \\
\text { Shift } \\
\mathrm{C}_{\mathrm{i}} \text { once }\end{array}$ & $\begin{array}{c}\text { ASCII } \\
\text { Equivalent } \\
\text { Of } \\
\mathrm{C}_{\mathrm{i}}\end{array}$ & $\begin{array}{c}\text { Subtract } \\
\text { Key value } \\
\mathrm{K}_{\mathrm{j}} \text { from } \\
\mathrm{C}_{\mathrm{i}}\end{array}$ & $\begin{array}{c}\text { Resultant } \\
\text { Plaintext } \\
\text { Character } \\
\mathrm{P}_{\mathrm{i}}\end{array}$ \\
\hline 113 & 01110001 & 10001110 & 01000111 & 71 & 46 & $\mathrm{~N}$ \\
\hline 81 & 01010001 & 10101110 & 01010111 & 87 & 37 & $\mathrm{E}$ \\
\hline 01 & 00000001 & 11111110 & 01111111 & 127 & 52 & $\mathrm{~T}$ \\
\hline 200 & 11001000 & 00110111 & 10011011 & 155 & 55 & $\mathrm{~W}$ \\
\hline 166 & 10100110 & 01011001 & 10101100 & 172 & 47 & $\mathrm{O}$ \\
\hline 105 & 01101001 & 10010110 & 01001011 & 75 & 50 & $\mathrm{R}$ \\
\hline 69 & 01000101 & 10111010 & 01011101 & 93 & 43 & $\mathrm{~K}$ \\
\hline
\end{tabular}


Example 2: Consider the plaintext message "CIPHER".

The Encryption and Decryption results produced by the Algorithm are as follows:

Table 3: Encryption

\begin{tabular}{|c|c|c|c|c|c|c|}
\hline $\begin{array}{c}\text { Plaintext } \\
\text { Character }\end{array}$ & $\begin{array}{c}\text { ASCII } \\
\text { Value }\end{array}$ & $\begin{array}{c}\text { Binary } \\
\text { Equivalent }\end{array}$ & $\begin{array}{c}\text { Add key Value } \\
\text { Let } \mathrm{K}=25 \\
\mathrm{C}_{\mathrm{i}}=\mathrm{P}_{\mathrm{i}}+\mathrm{K}_{\mathrm{j}} \\
1 \leq \mathrm{i} \leq \mathrm{n} \\
\mathrm{j} \leq \mathrm{mod} 6\end{array}$ & $\begin{array}{c}\text { Left } \\
\text { Shift } \\
\mathrm{C}_{\mathrm{i}} \\
=\mathrm{C}_{\mathrm{i}}{ }_{\mathrm{i}}\end{array}$ & $\begin{array}{c}\text { Complement } \\
\mathrm{C}^{1}{ }_{\mathrm{i}} \\
=\mathrm{C}_{\mathrm{i} \text { final }}\end{array}$ & $\begin{array}{c}\text { ASCII } \\
\text { Equivalent } \\
\text { value of } \\
\text { Ciphertext }\end{array}$ \\
\hline $\mathrm{C}$ & 67 & 01000011 & 92 & 10111000 & 01000111 & 71 \\
\hline $\mathrm{I}$ & 73 & 01001001 & 123 & 11110110 & 00001001 & 09 \\
\hline $\mathrm{P}$ & 80 & 01010000 & 155 & 00110111 & 11001000 & 200 \\
\hline $\mathrm{E}$ & 72 & 01001000 & 172 & 01011001 & 10100110 & 166 \\
\hline $\mathrm{R}$ & 69 & 01000101 & 194 & 10000101 & 01111010 & 122 \\
\hline
\end{tabular}

Table 4: Decryption

\begin{tabular}{|c|c|c|c|c|c|c|}
\hline $\begin{array}{c}\text { ASCII } \\
\text { Equivalent value } \\
\text { of Ciphertext }\end{array}$ & $\begin{array}{c}\text { Binary } \\
\text { Equivalent } \\
\text { Of } \mathrm{C}_{\mathrm{i}}\end{array}$ & $\begin{array}{c}\text { Complement } \\
\mathrm{C}_{\mathrm{i}}\end{array}$ & $\begin{array}{c}\text { Right } \\
\text { Shift } \\
\text { C }_{\mathrm{i}} \text { once }\end{array}$ & $\begin{array}{c}\text { ASCII } \\
\text { Equivalent } \\
\text { Of } \\
\mathrm{C}_{\mathrm{i}}\end{array}$ & $\begin{array}{c}\text { Subtract } \\
\text { Key value } \\
\mathrm{K}_{\mathrm{j}} \text { from } \\
\mathrm{C}_{\mathrm{i}}\end{array}$ & $\begin{array}{c}\text { Resultant } \\
\text { Plaintext } \\
\text { Character } \\
\mathrm{P}_{\mathrm{i}}\end{array}$ \\
\hline 71 & 01000111 & 10111000 & 01011100 & 92 & 67 & $\mathrm{C}$ \\
\hline 09 & 00001001 & 11110110 & 01111011 & 123 & 73 & I \\
\hline 200 & 11001000 & 00110111 & 10011011 & 155 & 80 & $\mathrm{P}$ \\
\hline 166 & 10100110 & 01011001 & 10101100 & 172 & 72 & $\mathrm{H}$ \\
\hline 122 & 01111010 & 10000101 & 11000010 & 194 & 69 & $\mathrm{E}$ \\
\hline 41 & 00101001 & 11010110 & 01101011 & 107 & 82 & $\mathrm{R}$ \\
\hline
\end{tabular}

\section{FEATURES OF THE SCHEME}

* Involve simple coding

* Low processing delay

* Simple to analyze

* Incorporates both substitution and transposition

* Fast response.

\section{CONCLUSION}

The security aspect is a more important in data communications over internet-works. Active attacks involve both modification and fabrication of messages. The goal of the encryption algorithm designing is to frustrate the hackers and makes the cryptanalysis difficult. The key value play more important role in encryption process. The processing speed,coding factors also plays a very important role. Using different key values for encrypting consecutive characters of plaintext hides the relationship between the ciphertext and plaintext. Altering each value of the ciphertext generated to get the final ciphertext make the cryptanalysis still more complex.The algorithm provides appreciable data security and requires minimum coding .The algorithm can be applied to message of any length.

\section{REFERENCE}

[1] Information Security: Text Encryption and Decryption with Poly Substitution method and combining features of cryptography.-R.Venkateswaram, Dr.V.Sundaram , June 2010

[2] A modified Hill cipher Involving Interweaving and Iteration.- V. Umakanta Sastry, N. Ravi Shankar and S. Durga Bhavani , July 2010.

[3] A block cipher having a key on one side of plaintext Matrix and its Inverse on the other side. Dr. V. U. K. Sastry, Prof. D. S. R. Murthy, Dr. S. Durga Bhavani .

[4] Cryptography and Network Security Principles and Practices, Third Edition - William Stallings

[5] Applied Cryptography Protocols, Algorithms and Source Coding BRUE SCHNEIER, Second Edition, John Wiley \& Sons, Inc.

[6] Introduction to Modern Cryptography, Jonathan Katz, Yehuda Lindell Chapman \& Hall / CRC Taylor R Francis Group. 